\title{
Nanostructuring and surface hardening of structural steels by ultrasonic impact- frictional treatment
}

Cite as: AIP Conference Proceedings 2053, 020006 (2018); https://doi.org/10.1063/1.5084352

Published Online: 19 December 2018

A. V. Makarov, R. A. Savrai, I. Yu. Malygina, E. G. Volkova, and S. V. Burov

\section{ARTICLES YOU MAY BE INTERESTED IN}

Layered metal composites with high resistance to brittle fracture at low temperatures AIP Conference Proceedings 2053, 020003 (2018); https://doi.org/10.1063/1.5084349

The influence of martensite content on acoustic, magnetic and electrical properties of chromium-nickel steel

AIP Conference Proceedings 2053, 020007 (2018); https://doi.org/10.1063/1.5084353

Discrete and continual approaches to the description of random microstructure of materials AIP Conference Proceedings 2053, 020001 (2018); https://doi.org/10.1063/1.5084347

\section{Conference Proceedings}

Get $30 \%$ off all print proceedings!

\section{Enter Promotion Code P/DF=30 at checkout}

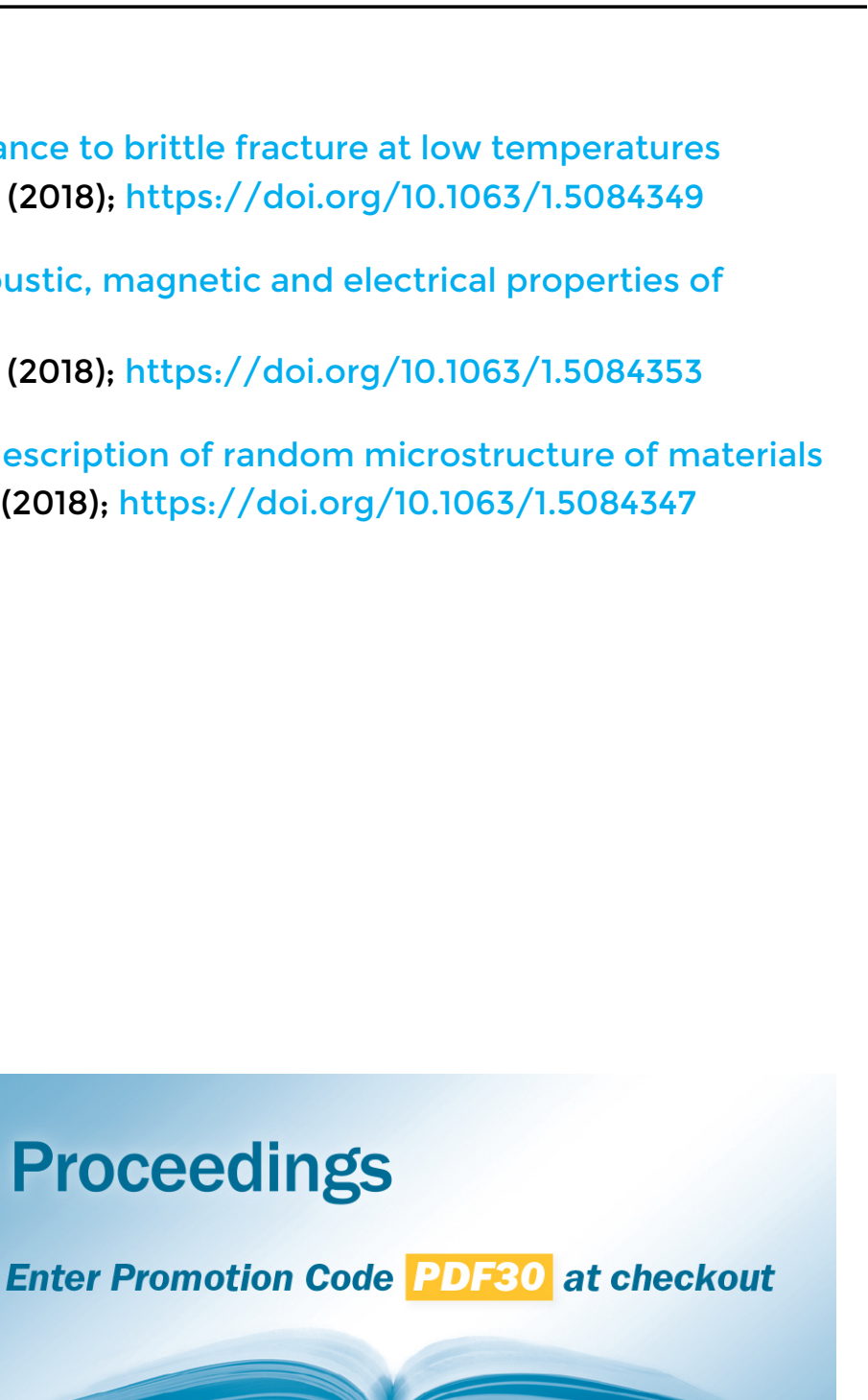




\title{
Nanostructuring and Surface Hardening of Structural Steels by Ultrasonic Impact-Frictional Treatment
}

\author{
A. V. Makarov ${ }^{1,2,3, a)}$, R. A. Savrai ${ }^{2}$, I. Yu. Malygina ${ }^{2}$, E. G. Volkova ${ }^{1}$, and \\ S. V. Burov ${ }^{2}$ \\ ${ }^{1}$ M. N. Miheev Institute of Metal Physics, Ural Branch of the Russian Academy of Sciences, \\ 18 S. Kovalevskoy St., Ekaterinburg, 620108, Russia \\ ${ }^{2}$ Institute of Engineering Science, Ural Branch of the Russian Academy of Sciences, \\ 34 Komsomolskaya St., Ekaterinburg, 620049, Russia \\ ${ }^{3}$ B. N. Yeltsin Ural Federal University, 19 Mira St., Ekaterinburg, 620002 Russia \\ ${ }^{\text {a)} C o r r e s p o n d i n g ~ a u t h o r: ~ a v m @ i m p . u r a n . r u ~}$
}

\begin{abstract}
With two structural steels (the steels 50 and 09G2S) as examples, the paper studies the effectiveness of a new method of ultrasonic impact-frictional treatment (UIFT) for the hardening and nanostructuring of the surface layer with the variation of the tilt angle of the vibrating indenter and the treatment environment. It is demonstrated that treatment with tool tilt angles different from $90^{\circ}$ and with the absence of a contact liquid results in the formation of a nanostructured surface layer with increased microhardness.
\end{abstract}

\section{INTRODUCTION}

Methods of intensive surface plastic deformation are currently being actively developed to provide hardening of metals and alloys due to the formation of submicro- and nanocrystalline structures in their surface layer. Such promising methods for surface nanostructuring of metal materials as frictional treatment by a sliding indenter $[1,2]$ and ultrasonic treatment with a vibrating tool [3-5] have a high potential of practical applications. The most important factors of effective nanostructuring and strain hardening of a surface layer are as follows: 1) normal load sufficient for the formation a new rough surface, as well as multiplicity of the deformation effect for the accumulation of strain $[6,7] ; 2$ ) inhomogeneous shear deformation with a sharp gradient [8]; 3) a high friction coefficient to enhance shear deformation [9, 10]; 4) noncorrosive environment to prevent embrittlement by atmospheric oxygen followed by the failure of the diffusely active nanostructured layer [11]. These factors govern the conditions for the implementation of the rotational mechanism of plastic deformation, which is responsible for the nanostructuring of metallic materials.

A new method for surface nanostructuring and hardening - ultrasonic impact-frictional treatment (UIFT) [12] has been devised on the basis of the above-mentioned approaches. The method develops the well-known strainhardening technique - standard ultrasonic impact treatment (UIT), which is generally performed with lubrication and the action of an indenter vibrating with ultrasonic frequency $f$ along the normal to the surface being treated (Fig. 1a). As distinct from UIT, UIFT is performed, firstly, by an oblique impact of a pulsing indenter (at an angle less than $90^{\circ}$ to the surface under treatment), Fig. 1b, c. This makes it possible to enhance the friction component of the indenter-metal interaction and, accordingly, to increase the shear component of plastic strain. Secondly, it is suggested that UIFT should be performed without contact liquid in order to provide a higher strain of the surface layer due to an increased friction coefficient (friction force) and with the use of a protective gas environment preventing oxygen embrittlement of a fine-grained surface layer. This increases the hardening and thickness of the hardened layer. The aim of the paper is to study the regularities in the hardening of the structural steels 50 and 09G2S undergoing UIFT at different tool tilt angles and in different environments.

Mechanics, Resource and Diagnostics of Materials and Structures (MRDMS-2018) AIP Conf. Proc. 2053, 020006-1-020006-5; https://doi.org/10.1063/1.5084352 Published by AIP Publishing. 978-0-7354-1781-6/\$30.00 


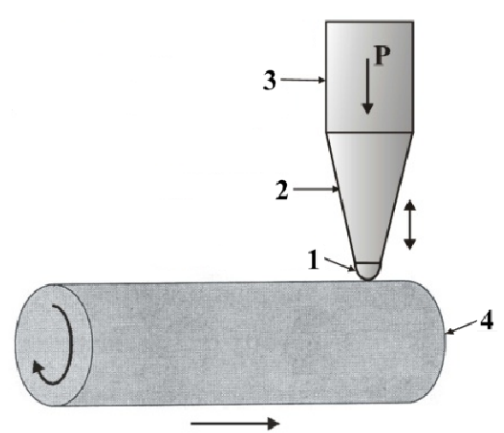

(a)

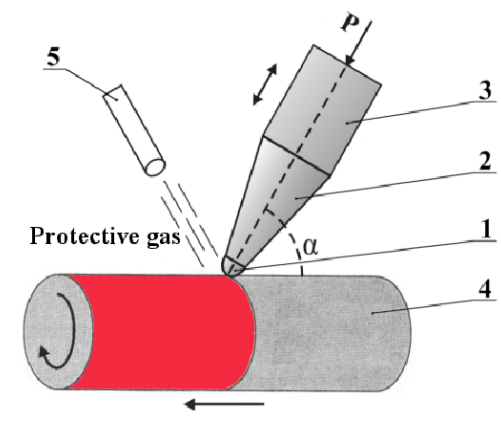

(b)

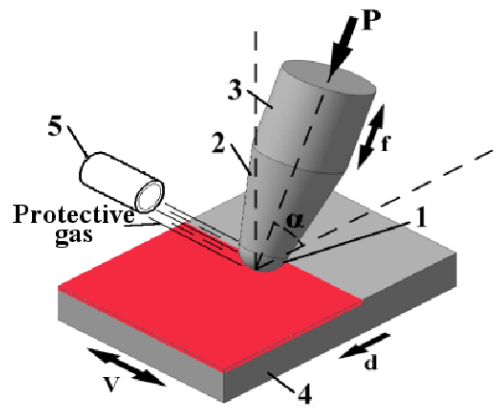

(c)

FIGURE 1. Schemes of standard UIT (a) and UIFT of cylindrical (b) and flat (c) surfaces: 1 - tool (indenter); 2 - waveguide; 3 - magnetostrictive or piezoelectric transducer; 4 - part or specimen; 5 - tube for protective gas feeding

\section{EXPERIMENTAL PROCEDURE}

Samples of the structural steels $50(0.51 \% \mathrm{C})$ and $09 \mathrm{G} 2 \mathrm{~S}(0.12 \% \mathrm{C} ; 1.12 \% \mathrm{Mn} ; 0.72 \% \mathrm{Si})$ were studied. Specimens sized $70 \times 40 \times 5 \mathrm{~mm}$ were cut out from the steels and subjected to heat treatment (steel 50), mechanical grinding, electrolytic polishing and ultrasonic treatments. Heat treatment of the 50 steel consisted in quenching followed by tempering at $350{ }^{\circ} \mathrm{C}$; the $09 \mathrm{G} 2 \mathrm{~S}$ steel was used as received, with a ferrite-pearlite structure. Ultrasonic treatment was performed on an Il-4/1-2 device equipped with a magnetostrictive transducer with an exponential acoustic transformer and a numerically controlled coordinate table. The flat surfaces of the specimens were treated by scanning (with a transverse displacement) with a spherically ground hard-alloy indenter, with a radius of $4 \mathrm{~mm}$, preliminarily forced with the static load $P=100 \mathrm{~N}$ (for the 50 steel) and $P=170 \mathrm{~N}$ (for 09G2S) against the surface to be treated, at the ultrasonic vibration frequency $f=21.5 \mathrm{kHz}$. The I-30 Industrial oil, air and argon were used as a lubricant-cooling process medium. The treatment was performed both along the normal $\left(\alpha=90^{\circ}\right)$ to the steel surface (UIT) and at the angles $\alpha=80-55^{\circ}$ to the surface (UIFT). The average velocity of the vibrating indenter was $V=36$ and $10 \mathrm{~mm} / \mathrm{s}$ for the 50 and $09 \mathrm{G} 2 \mathrm{~S}$ steels, respectively. The step of the transverse displacement of the scanning indenter was $d=0.1$ and $0.2 \mathrm{~mm}$ for the 50 and 09G2S steels, respectively. Microhardness was determined on a Shimadzu HMV-G21DT microhardness tester under a load of $0.245 \mathrm{~N}$ on the Vickers indenter. The microstructure was examined by scanning electron microscopy (SEM) on a Tescan Vega II XMU microscope and by transmission electron microscopy (TEM) on a JEM-200CX microscope, with mechanical and electrolytic thinning of the workpieces (foils).

\section{RESULTS AND DISCUSSION}

Figure 2 shows the initial coarse-grained microstructure of the medium-carbon 50 steel quenched and tempered at $350^{\circ} \mathrm{C}$ (a), as well as the general view (b) and microstructure of the surface layer (b-f) hardened by UIFT in air at $\alpha=70^{\circ}$. The total thickness of the deformed layer $h$ is seen to be $\sim 25 \mu \mathrm{m}$ (Fig. 2b), and in the $\sim 5-7 \mu \mathrm{m}$ thick surface layer there appears a predominantly nanocrystalline structure (Fig. 2c). Electron diffraction (Fig. 3d), besides $\alpha-$ phase reflections in the form of rings formed by reflections from numerous nanocrystallites sized below $100 \mathrm{~nm}$ (Fig. 2e), shows separate $\mathrm{Fe}_{3} \mathrm{C}$ reflections. This indicates an incomplete strain-induced dissolution of cementite, which remains intact in the structure in the form of nanoparticles (Fig. 2f).

Figure 3 presents the microhardness of the 50 steel surface after standard UIT in oil along the normal to the surface $\left(\alpha=90^{\circ}\right)$ and after UIFT in air and in argon at different tool tilt angles $\alpha$. It is obvious that the lowest hardening (below $560 \mathrm{HV} 0.025$ ) is observed for standard UIT in oil at $\alpha=90^{\circ}$. When UIFT is performed in gas environments, a decrease in the angle $\alpha$ leads to an increase in the microhardness of the steel surface, with a maximum microhardness of $1020 \mathrm{HV} 0.025$ being reached after treatment with a hard-alloy indenter in argon at $\alpha=70^{\circ}$. Under UIFT in air, the highest microhardness $960 \mathrm{HV} 0.025$ is reached at $\alpha=60^{\circ}$. The further decrease of $\alpha$ to $55^{\circ}$ causes a certain decrease in the microhardness of the hardened surface (to 850 and $900 \mathrm{HV} 0.025$ after UIFT in air and in argon, respectively) (Fig. 3), which results from excessive strain-hardening of the surface layer and the appearance of damages weakening the metal. 


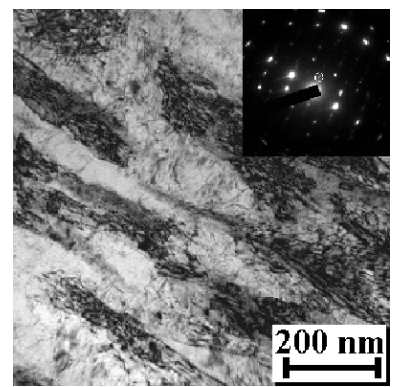

(a)

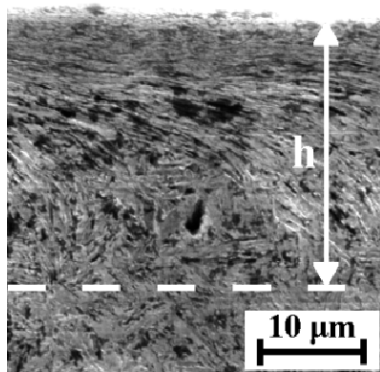

(b)

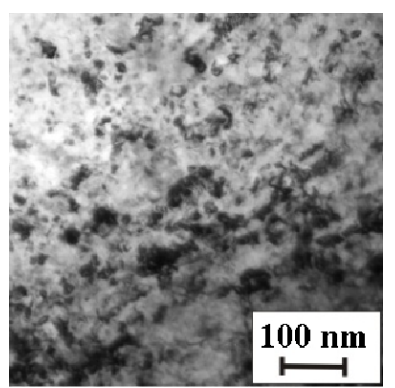

(c)

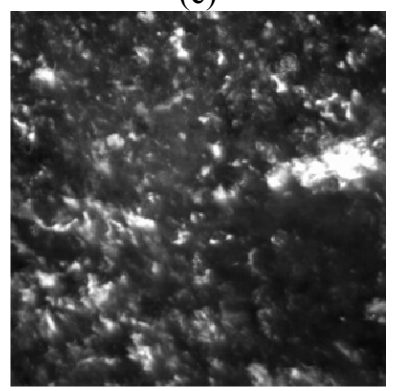

(e)

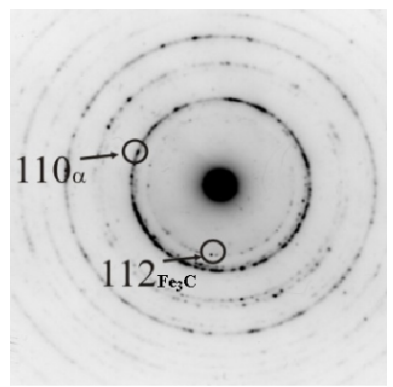

(d)

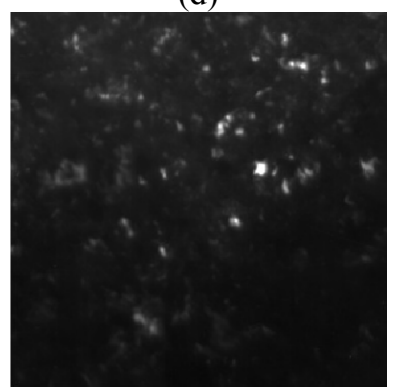

(f)

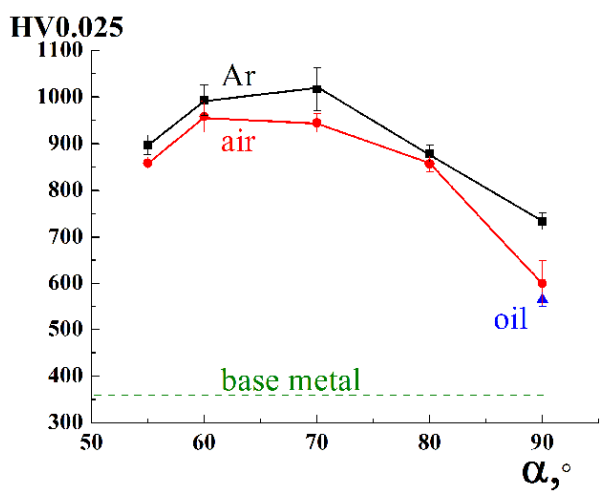

FIGURE 3. Effect of the tool tilt angle $\alpha$ and the ultrasonic treatment environment on the microhardness of the 50 steel surface
The initial microstructure of the as-received low-carbon 09G2S steel is represented by ferrite grains (Fig. 4a) and sparse pearlitic colonies (Fig. 4b). After ultrasonic treatment in oil, even at $\alpha=70^{\circ}$ there is only fragmentation of separate ferrite grains (Fig. 4c) and cementite plates in the pearlite colonies (Fig. 4d), with the electron diffractions consisting of separate reflections. This is due to the lower friction coefficient when there is a lubricant in the tool-surface contact zone. As a result, the friction component of the tool-metal interaction decreases, and hence so does the shear component of plastic strain. Therefore, there is no any noticeable steel surface hardening.

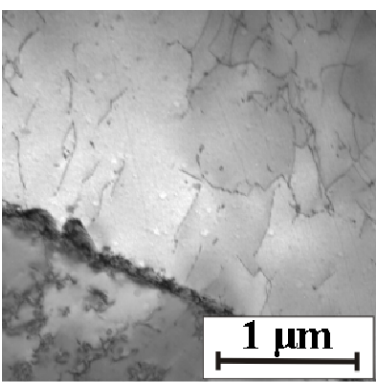

(a)

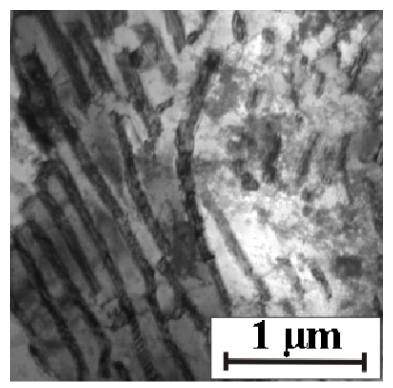

(b)

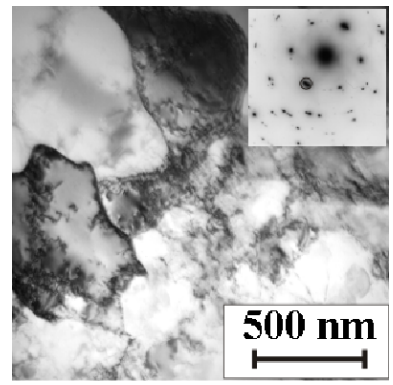

(c)

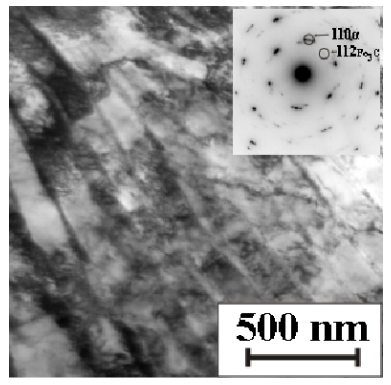

(d)

FIGURE 4. The structure (TEM) of the $09 \mathrm{G} 2 \mathrm{~S}$ steel in the initial state $(\mathrm{a}, \mathrm{b})$ and after ultrasonic treatment in oil at $\alpha=70^{\circ}(\mathrm{c}, \mathrm{d})$ : a, c - ferrite grains; b, d-pearlite colonies; bright-field images

As distinct from treatment in oil, UIFT increases the microhardness of the 09G2S steel surface considerably (to 415 HV0.025 for UIFT in argon) (Fig. 5). As the distance from the surface increases, the total level of microhardness decreases, the sharpest decrease being observed in a $20 \mu \mathrm{m}$ thick layer; then, down to a depth of 
$100 \mu \mathrm{m}$, the microhardness remains at the level of $315 \mathrm{HV} 0.025$ and then smoothly decreases to the initial level of $250 \mathrm{HV} 0.025$ at a depth of $\sim 170 \mu \mathrm{m}$.

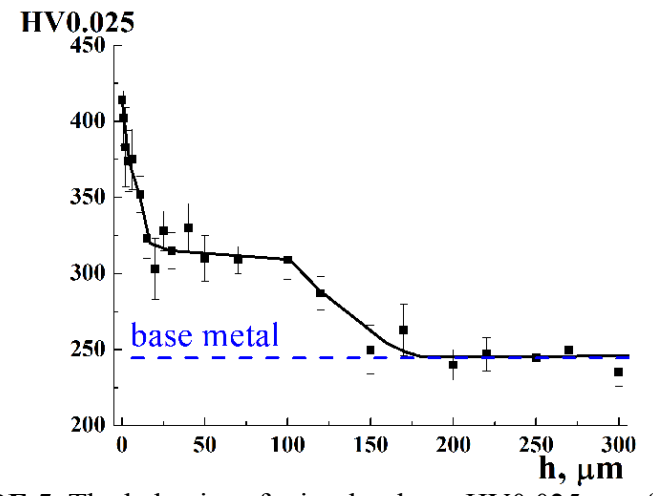

FIGURE 5. The behavior of microhardness HV0.025 as a function of the distance from the surface $h$ of the 09G2S steel specimen after UIFT in argon at $\alpha=80^{\circ}$

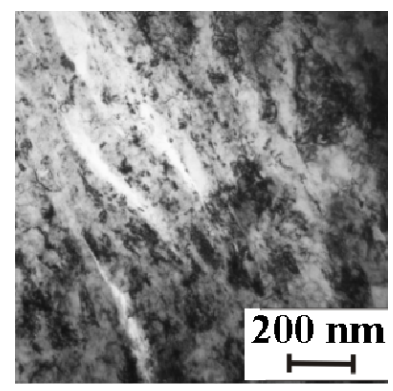

(a)

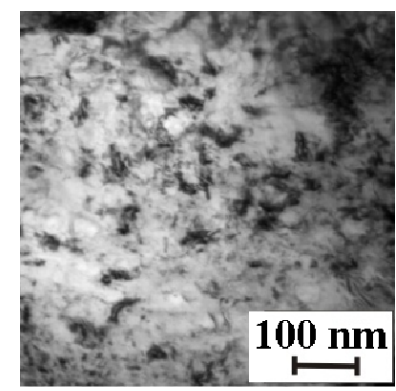

(b)

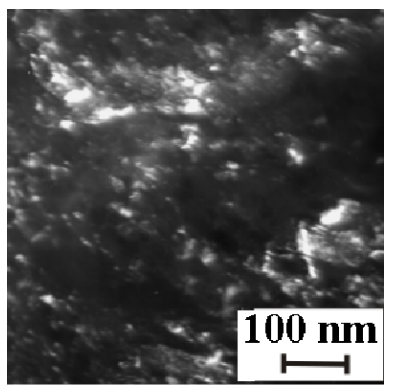

(c)

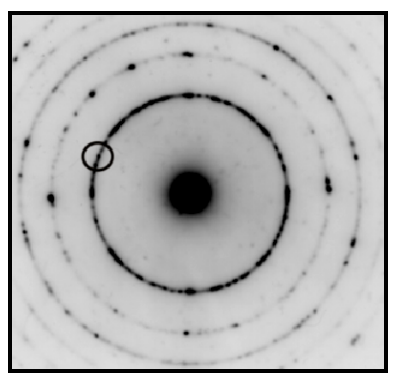

(d)

FIGURE 6. The structure of the 09G2S steel surface layer after UIFT in air at $\alpha=75^{\circ}$ (a) and in argon at $\alpha=80^{\circ}$ (b-d): $\mathrm{a}, \mathrm{b}$ - bright-field images; $\mathrm{c}-\mathrm{a}$ dark-field image in the (110) $\alpha$ reflection; $\mathrm{d}$ - electron diffraction (TEM)

\section{CONCLUSIONS}

A new technology of ultrasonic impact-frictional treatment (UIFT) [12] has been proposed, which is effected by an oblique impact of a pulsing indenter without lubrication, as distinct from the standard ultrasonic impact treatment (UIT) performed in oil with an indenter acting along the normal (at an angle of $90^{\circ}$ ) to the surface being treated. It has been demonstrated that UIFT with the use of a spherically ground hard-alloy indenter in an argon environment and in air at a tool tilt angle of $80-55^{\circ}$ to the surface provides a much greater increase in the microhardness of the surface layer of the 50 (to $1020 \mathrm{HV} 0.025$ ) and $09 \mathrm{G} 2 \mathrm{~S}$ (to $415 \mathrm{HV} 0.025$ ) structural steels as compared to standard UIT. The electron microscopic examination has revealed the formation of a nanostructured layer on the surface of the steels under UIFT, this being the most important reason for the effective hardening of the steel surface processed by UIFT.

\section{ACKNOWLEDGMENTS}

The work was done within the state order of FASO Russia on the subjects "Structure", No. AAAA-A18118020190116-6 (project No. 18-10-2-39) and the government assignment for IES UB RAS, theme No. AAAAA18-118020790147-4. Transmission electron microscopy was performed in the "Elektronnaya Mikroskopiya" collective use center of UB RAS, the Electron Microscopy division of the Testing Center of Nanotechnologies and Promising Materials affiliated to the Institute of Metal Physics UB RAS. Scanning electron microscopy and microhardness tests were performed in the "Plastometriya" collective use center of the Institute of Engineering Science UB RAS. 


\section{REFERENCES}

1. A. V. Makarov, L. G. Korshunov, I. Yu. Malygina, I. L. Solodova, Metal Science and Heat Treatment 49 (34), 150-156 (2007).

2. A. V. Makarov, L. G. Korshunov, V. B. Vykhodets, T. E. Kurennykh, R. A. Savrai, Phys. Met. Metallogr. 110 (5), 507-521 (2010).

3. I. H. Cho, G. H. Song, C. S. Kim, J. Mech. Sci. and Tech. 19, 2151-2156 (2005).

4. V. E. Panin, V. P. Sergeev, A. V. Panin, Yu. I. Pochivalov, Phys. Met. Metallogr. 104 (6), 627-636 (2007).

5. A. V. Panin, M. S. Kazachenok, A. I. Kozelskaya, R. R. Balokhonov, V. A. Romanova, O. B. Perevalova, Yu. I. Pochivalov, Mater. Des. 117, 371-381 (2017).

6. V. P. Kuznetsov, A. V. Makarov, S. G. Psakhie, R. A. Savrai, I. Yu. Malygina, N. A. Davydova, Phys. Mesomech. 17 (4), 250-264 (2014).

7. A. V. Makarov, P. A. Skorynina, A. S. Yurovskikh, A. L. Osintseva, Phys. Met. Metallogr. 118 (12), 1225-1235 (2017).

8. J. G. Li, M. Umemoto, Y. Todaka, K. Tsuchiya, J. Alloys Comp. 434-435, 290-293 (2007).

9. A. V. Makarov, R. A. Savrai, N. A. Pozdejeva, S. V. Smirnov, D. I. Vichuzhanin, L. G. Korshunov, I. Yu. Malygina, Surf. Coat. Technol. 205 (3), 841-852 (2010).

10. D. A. Vychuzhanin, A. V. Makarov, S. V. Smirnov, N. A. Pozdeeva, I. Yu. Malygina, J. Mach. Manufact. Reliab. 40 (6), 554-560 (2011).

11. L. G. Korshunov, A. V. Makarov, N. L. Chernenko, Phys. Met. Metallogr. 90, Suppl. 1, S48-S58 (2000).

12. A. V. Makarov, I. Yu. Malygina, S. V. Burov and R. A. Savrai, R. F. Patent No. 2643289 (2018). 